\title{
A Network-based Tool for Identifying Knowledge Risks in Data-Driven Business Models
}

\author{
Michael Fruhwirth \\ Know-Center $\mathrm{GmbH}$ \\ mfruhwirth@know-center.at
}

\author{
Viktoria Pammer-Schindler \\ Graz University of Technology \& \\ Know-Center GmbH \\ viktoria.pammer-schindler@tugraz.at
}

\author{
Stefan Thalmann \\ University of Graz \\ stefan.thalmann@uni-graz.at
}

\begin{abstract}
Data-driven technologies enable organizations to innovate new services and business models and thus hold the potential for new sources of revenue and business growth. However, such new data-driven business models impose new ways for unwanted knowledge spillovers. Current research on datadriven business models and knowledge risks provides little help to identify and discuss such novel risks within the innovation process. We have developed a network-based representation of data-driven business models within one case organization, where it helped to identify knowledge risks in the design process of data-driven business models. In this paper, we further evaluated the artifact through 17 interviews with experts from the domain of business models, data analytics and knowledge management. We found that the network-based representation is suitable to visualize, discuss and create awareness for knowledge risks and see types of data-related value objects and quantification of risks as two recommendations for further research.
\end{abstract}

\section{Introduction}

The increasing amount of data available and the advances in data analytics enable organizations to improve their existing business models and to create new offerings [50]. Such data-driven business models (DDBMs) based on data analytics not only hold the opportunity for business growth and new revenues for organizations [9], they might also cause new types of risks in regard to data. Methods from data analytics and machine learning are used to generate insights from data (e.g. through predictions or recommendations) and form the basis of an offering. Depending on the degree of analytics, the offering could be a report or visualization of descriptive data analysis, support for further decisions or actions in form of recommendations or predictions [38] or even machine learning models [22]. To create such models, knowledge on the domain is required and materialized in those models. Such an offering or specifically exchange of data, insights, or models, what we further refer to data-related value objects may cause knowledge risks in DDBMs.

We already found evidence for such knowledge risks within one case study [15]. Based on this, we frame the problem as follows: Knowledge risks in data-driven business models occur when valuable knowledge of a company is materialized in datarelated value objects (e.g., algorithms, models, insights, predictions, or recommendations) and used as the basis of an offering. Through the exchange of such objects, critical knowledge may leak the organization's boundary and put the company's competitive advantage at risk. Thus, from a risk management perspective, managers need support to identify and manage such risks in the design process of DDBMs.

Current research on tool support for innovating DDBMs is mainly focusing on supporting idea generation and the design process [16]. Likewise, risks and risk management in business model innovation is an under-researched field [5]. Further, novel risks evolving from business models based on digital technologies make new risk management frameworks and tools necessary [10].

To address this gap, in line with the call for more research on managing knowledge risks in strategic Information Systems (IS) settings [31] and the call for research in IS on tooling for risk management in business model innovation based on digital technologies [44], we have developed an artifact to identify knowledge risks in DDBMs in a Design Science Research project within one case organization [15]. The essence of the artifact is a network-based representation of a business model, i.e. it emphasizes the flows of value objects between business actors. In this case, the artifact was found to be useful to discuss and identify knowledge risks.

In the present paper, we further evaluate this artifact in order to generalize from development and validation in a single case; and ask the following 
research question in this paper: Can a networkedbased representation of business models provide support for identifying and understanding knowledge risks in data-driven business models?

To answer this research question, we conducted an interview study with 17 experts from industry and academia to evaluate the ease of use in terms of structure and understandability as well as the perceived benefit and problem fit of our artifact.

The rest of this paper is structured as follows: Section two provides the background and related work for this study. A brief description of the overall Design Science Research project, the initial artifact and the applied interview evaluation method follows in section three. Subsequently, section four presents the findings from the artifact evaluation including recommendations on the artifact design from the interviewees. The paper closes with a discussion and outlook in section five.

\section{Background and Related Work}

Organizations have to find an appropriate business model to capture value from new technologies [8] and to ensure competitive advantage [2]. Business models can be understood as an "architecture for the product, service and information flows, including a description of the various business actors and their roles; and a description of the potential benefits for the various actors; and description of the sources of revenue" [46]. Datadriven business models (DDBMs), in particular, describe a new type of business models [19] where data is used as a key resource $[13,20]$ to generate insights with the aid of data analytics methods [23] that form the basis for a value proposition [29]. Data represents here both a firm's resource [20] and a flow across business actors [43]. Organizations can develop new business models with the aid of business model innovation [7], i.e. experimenting with new business model designs [8]. Data-driven business model innovation in particular is understood "as the process when an organization adopts a novel approach to commercialize data as its new underlying asset to deliver value to existing or new customers" [16].

In general, tools and methods, supporting managers and organizations in business model innovation [3, 37] through the visualization [42] or the evaluation of business models [44], are available. However, the evaluation of business models should not only focus on the estimation of returns, but also on identifying relevant risk factors, such as knowledge risks, in a business model [5]. Existing research on DDBMs in general and tools and methods in particular, is predominantly focusing on tools and methods to support idea generation [16]. Literature provides several "canvas" or "maps" to structure ideation workshops or communicate ideas (e.g., [28] or [29]). However, there is a lack of support for decision making, including risk management, in innovating DDBMs [16].

During the design of (data-driven) business models, business managers have to find a balance between estimated return and acceptable risk in their business model design choices $[6,44]$. Identifying risk factors within a new or existing business model enables decision makers to adopt the business model design or to take proper measures [5]. One type of such risks in business models is the drainage of intellectual property or know-how from the business model owner [5]. Knowledge management literature denotes such events as knowledge risks [11, 32].

The management of knowledge risks, i.e., knowledge protection, is considered as one core strategy of knowledge management [31]. Knowledge risks can arise from human, operational or technological factors [12] and their management is crucial for organizations because knowledge typically forms the core of the competitive edge [26]. Current knowledge risk literature is mainly focused on preventive measures; however, managing knowledge risks also requires preventive measures, like contingency plans for a leakage [45]. Knowledge protection literature focused very much on explicit and document knowledge in organizations so far and neglected tacit knowledge [32] as well as knowledge which is embodied in data streams [25]. Especially the latter becomes more and more important with rising digitization [12].

Knowledge risks can arise from shared data sets in data-centric collaborations or digital supply chains $[27,49]$. It is challenging for organizations to be aware of which knowledge could be extracted out of shared data sets via data analytics methods by other actors leading to unintended knowledge leakage [25, 49]. Managing such knowledge risks require, legal, organizational or technical measures [49]. For instance, grey-box modelling together with a variety of more fine-granular knowledge protection practices have been found as potential solution to deal with knowledge risks in such data-centric collaboration in an in-depth investigation of knowledge protection practices in an industrial case study [27]. Of course, in data-centric collaborations as in DDBMs, not only data but also other data-related value objects such as predictions, models or their configuration are exchanged between actors [22]. The exchange of such value objects holds the potential for knowledge risks in DDBMs [15]. This diversity of knowledge risks 
requires a set of tools and methods "to identify, prevent or manage them" [12].

In the wider context of business models based on digital technologies that don't specifically focus on the exchange of data or data-derived value objects, a few studies that explicitly provide tools and methods for risk management exist. [10] provide a 4-steps risk management framework for innovation risks in digital business models. [4] provides an adopted method of the Value Network Analysis to identify risks in ecosystems of Internet of Things business models. And [5] provides a list of business model risk categories, such as data risks or intellectual property risks, that can be used by decision-makers as a checklist to identify risk and uncertainty factors in their business models to further adapt the business model design. Nevertheless, knowledge risks are missing in current literature reviews on business model innovation (e.g., [37] or [44]). Further knowledge management literature provides several tools and methods to manage knowledge risks, such as a knowledge risk management framework [33], a proactive process for managing knowledge security risks [24] or mapping information and knowledge assets for security risk assessment [35]. However, in the context of DDBMs such tools are scarce [16].

In this space, the present work evaluates the suitability of a network-based representation of business models to represent knowledge risks specifically in the case of DDBMs. The present work thereby complements the above literature by the investigation of an artifact for risk management in the development of DDBMs; and complements the few such existing artifacts in the wider space of business models that rely on computational technologies.

\section{Methodology}

Overall we follow a Design Science Research methodology [21, 36] to address the problem of knowledge risks in DDBMs and to provide sufficient support. We have identified the problem of knowledge risks within one case organization and developed and evaluated an artifact within this case [15] (see section 3.1). To further "observe and measure" [36], how well our artifact supports decision-makers in organizations to identify and manage knowledge risks in DDBMs, we follow a continuous evaluation approach [41, 48]. In the present study, we describe the evaluation of the artifact based on expert interviews (the focus of this study, see section 3.2), and derived design recommendations.

The investigation of the artifact in its application context, i.e. within organizations and business model innovation projects, in the sense of naturalistic evaluations, is subject of future research.

\subsection{Description of the Initial Artifact}

We created the initial artifact through four design iterations within one case organization in the automotive industry [15]. We represented DDBMs as a value network, including the elements of actors and exchanged values. An actor is "an independent economic (and often legal) entity" [18] and has one or several roles in the network, like the business model owner, a customer, a data provider, or another key partner. Actors are exchanging tangible and intangible value objects like money, data, knowledge, services, products, or other benefits. Further, the knowledge boundary is visualized to make the potential transfer

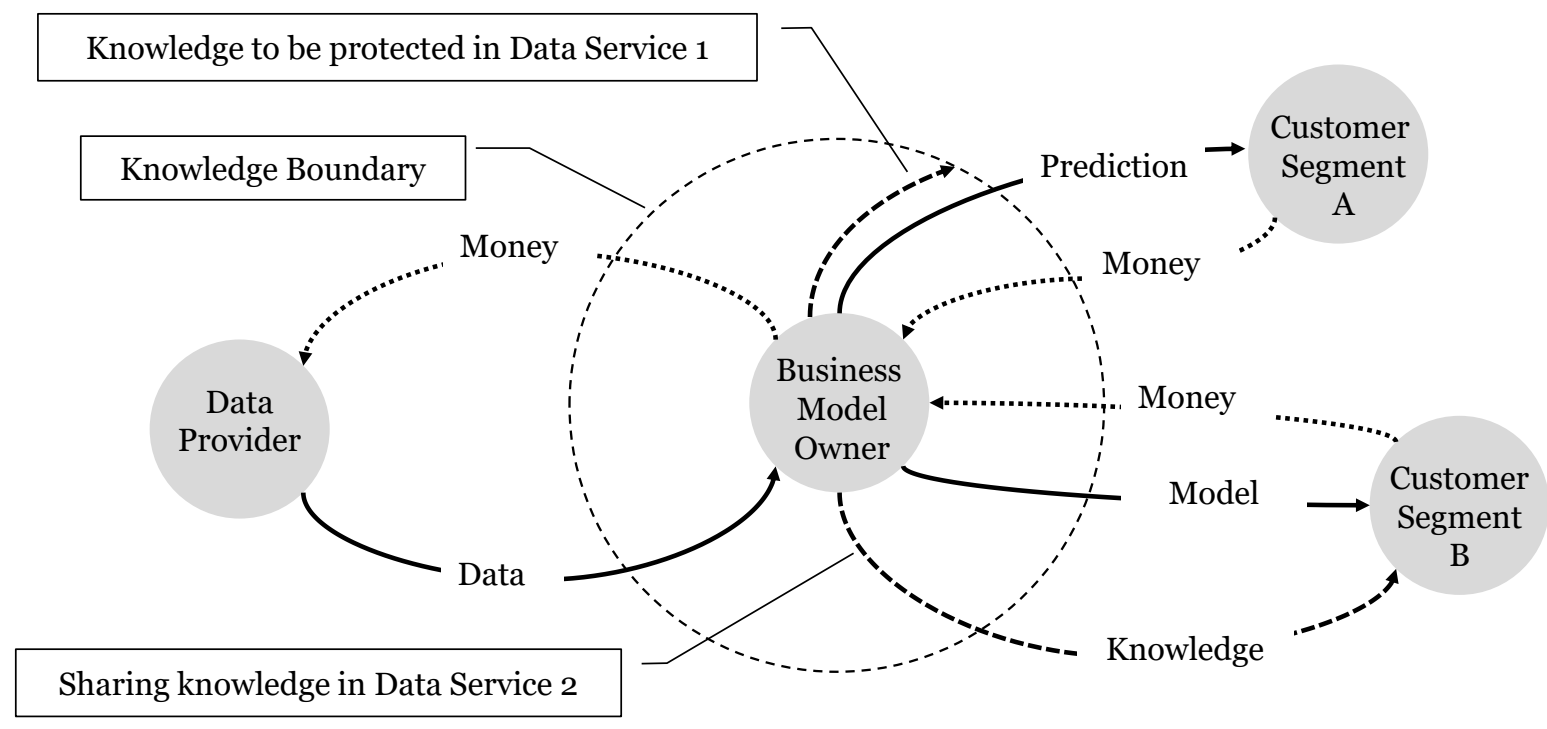

Figure 1. Representation of knowledge risks in the initial artifact [15]. 
of knowledge visible. The initial artifact design was informed by previous research on business models (like network-based representations of business models [4, 18, 43] and knowledge risks [30].

Figure 2 shows a fictitious modified example of a DDBM based on the case study to illustrate an instantiation of the artifact [15]. The actor Business Model Owner is acquiring data from a Data Provider in exchange for money to develop a model of a realworld phenomenon (i.e. predicting the residual lifetime of a novel technical component) based on his engineering knowledge, data from research projects, as well as data from a Data Provider. Thus, the Business Model Owner is materializing his core engineering knowledge in this data-driven model. This model enables several options for offerings by the Business Model Owner for customers A from Industry 1 and customers B from Industry 2. In case one, the Business Model Owner is offering the model as a service to Customer Segment A and is sharing only predictions and therefore can protect the knowledge materialized in the model. In case 2, the Business Model Owner is selling the model to Customer Segment $B$ from another industry and thus also sharing his core knowledge. We have presented here only the types of labels for simplification and retaining the anonymity of the original use case. In the real-world case, we have precisely named the flows and actors as suggested by [1].

\subsection{Artifact Evaluation through Expert Interviews}

To further qualitatively evaluate the structure and understandability as well as the perceived benefit of our artifact, we have chosen expert interviews as our evaluation method, as it enabled us to collect descriptive justificatory knowledge on the artifact design from experts who have experience in the domain, before applying the artifact into a naturalistic setting to proof its usefulness [41].

Via snowball sampling we selected 17 experts in the domains of Business Models (7), Data Science (9), and/or Knowledge Management (6) from academia (8) and industry (9) to collect feedback for our artifact from those related perspectives. Academic experts held positions as professors or senior researchers; and practitioners were working in the Automotive, Information Technology or Consulting industry and held technical or management positions. Table 1 gives an overview of the interview participants.

\footnotetext{
${ }^{1}$ Not mutually exclusive. One expert might have a background in more than one domain.
}

The semi-structured interviews were structured in two parts: in the first part, we explored and discussed the problem of knowledge risks in DDBMs to provide the application context and background for the innovation tool. In the second part, we first presented the artifact and an exemplary case, as described in section 3.1, and asked the experts questions regarding the structure and applicability of the artifact.

Table 1. Description of recruited participants in this interview evaluation study.

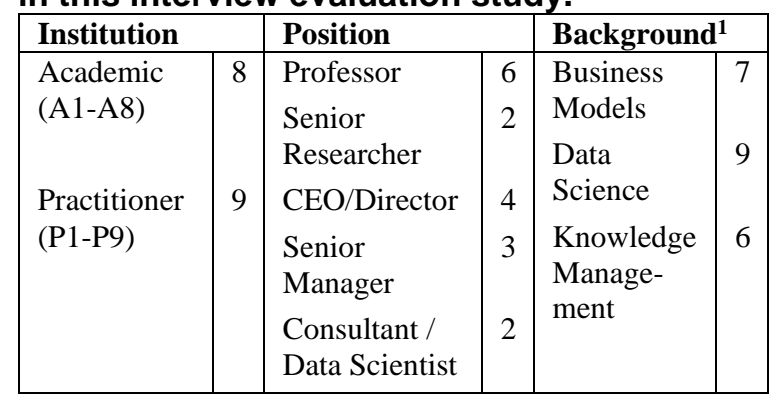

The evaluation of our artifact based on a single exemplary use case induced some limit on the generalizability of our results: one might argue, that findings are specific to the use case we have instantiated. Two characteristics of our study mitigate this limit: Firstly, we have interviewed experts with a variety of backgrounds. Hence, the exemplary case served as grounding and starting point for the discussion; of course, interviewees also gave feedback based on their own experience. Secondly, the exemplary use case corresponds to the anonymized version of a real business case. This implies on the one hand a realistic example, and on the other hand, through anonymization one that isn't domain-specific. Though, the scope was limited to use cases in the B2B environment with explicit money flows.

The interviews were conducted between November 2019 and May 2020 via face-to-face meetings or through digital communication software (such as Skype or GoToMeeting) in German or English. All interviews were audio-recorded and transcribed. To further analyze the text material from our interviews we applied the Qualitative Content Analysis approach suggested by [34]. As a starting point themes were defined corresponding to the goals of the evaluation and the questions asked in the interviews (e.g., relevance, structure of the artifact, understandability of the artifact or expected benefit). Categories were built inductively within these themes through coding of the interview material. The text was 
cleaned and passages without relevant content were dropped. Codes belonging to the same subject were consolidated under new categories. Quotes from interviews conducted in German were translated into English, overlooked by a second researcher and marked with a $(*)$ in the manuscript. Names of persons or organizations were replaced by pseudonyms to maintain anonymity. We describe the results of the interviews in the following section.

\section{Findings}

In this section we present the results of our data analysis of the transcripts from our artifact evaluation. First, we discuss the relevance of tool support for identifying knowledge risks during a DDBM innovation process. Secondly, we discuss the ease of use of the network-based representation in the sense of structure and understandability. Finally, we discuss the fit of the network-based representation to the problem of identifying knowledge risks during the DDBM innovation process.

\subsection{General Relevance of Use Case}

The challenge of knowledge risks in DDBMs, as outlined in the introduction, was generally perceived as a novel and relevant problem by the interviewed experts. As one consultant mentioned:

"Fundamentally, I do believe this is a risk. It's just that reconstructing knowledge is currently not a discipline that is often or prominent published. Because reverse engineering is in the European, Western world not a prominent engineering discipline. I'm pretty sure that companies are doing it." (P1*)

Further, the interviewee also highlighted that this reverse engineering of knowledge happens hidden. In this context, the interviewees mentioned their need for tool support to make the (potential) reverse engineering more transparent. It makes sense to consider such potential risks already during the design process of business models, which was the intention of the tool, as one industry consultant (P3) stated:

"If I initiate an innovation process to identify new business areas from data, it makes sense as a second step that I immediately go with such a tool and assess the business model not only from an business perspective, because that's what you usually do anyway, but also to accompany the risk [assessment] with such a tool. And to do that as part of the process and not at the end." (P3*)

Overall, the wish to perform the risk assessment as part of the design process seems important. One academic expert (A4) reported from one company in which analyzing risks was part of their strategy development process and thus in front of business model innovation. However, currently knowledge risks are assessed quite traditionally as one interviewee described:

"Risk management is actually more like simply working with lists. We calculate business cases on the basis of experience and of course we have assumptions regarding profitability; and the more sensitive the assumptions are on a business case, the higher we estimate the risk. And then we track that risk more or less with lists." (P7*)

This "hands-on" approach has clearly limitations if it comes to complex settings and hidden knowledge risks in big data sets. The interviewees are aware of this limitation and lack suitable guidelines and tool support:

"If you ask me, what sets of rules do we have to make sure, when we develop and sell models to our customers, that they are not somehow misused. There's still little available." (P4*)

Our interviewees showed awareness for knowledge risks and they articulated a need for systematically identifying and managing such risks that arise from the exchange of data-related value objects. However, currently there is a lack of guidance and tool support.

\subsection{Structure and Understandability}

Next, we presented our artifact with a synthetic case, created based on our experience from the case study [15] (i.e., abstracted from a real company but still reasonable), as described in Section 3.1 above. Generally, interviewees perceived the network-based approach as understandable and appropriate. The representation was sufficient to communicate the example and to discuss the knowledge risks with the experts. One industry expert (P5) brought up the suitability of the network-based representation:

"I think exactly this kind of network makes it clear that you have risks that differ from those that you have traditionally. And that's what it's all about. To say, you have to look at the data topic separately, because the nature of these risks is somewhat different compared to selling a classic product" (P5*)

The interviewee acknowledged the novelty of risks arising from data-driven collaborations and appreciates the additional perspective. Another industry expert (P7) highlighted to the benefit of extending the common representation with the dimension of data to identify and assess the impact of knowledge risks:

"Yes, all in all such network models are already established tools for representing business models. Therefore, it [this artifact] can be seen as extension of 
the already existing network tools with data, as one of various aspects, what it makes sense in any case to consider additionally, to develop business models iteratively. And I think the language you're using [...] is definitely appropriate." (P7*)

Our interviewees confirmed that the main elements of the artifact (the actors and flows of data, knowledge, money and benefits) are sufficient and easy to understand to describe, communicate and discuss the business model. The flow of money for instance was mentioned as necessary element to balance the estimated benefit with the expected risks.

However, there were several comments and recommendations to further subdivide the main elements on a more granular level. Table 2 gives a summary of the results structured by the category of design element and with exemplary evidence from the interviews, that are further discussed.

\section{Table 2. Identified recommendations for improvements of the artifact's structure.}

\begin{tabular}{|c|c|c|}
\hline $\begin{array}{l}\text { Artifact } \\
\text { Element }\end{array}$ & $\begin{array}{l}\text { Expert } \\
\text { recommendation }\end{array}$ & $\begin{array}{l}\text { Exemplary } \\
\text { evidence }\end{array}$ \\
\hline $\begin{array}{l}\text { Types of } \\
\text { data flows }\end{array}$ & $\begin{array}{l}\text { Subdivision of data flows } \\
\text { into different types of } \\
\text { data-related value objects }\end{array}$ & $\begin{array}{l}\mathrm{P} 1, \mathrm{P} 2, \mathrm{P} 5, \\
\mathrm{~A} 2\end{array}$ \\
\hline $\begin{array}{l}\text { Types of } \\
\text { knowledge }\end{array}$ & $\begin{array}{l}\text { Specification and } \\
\text { visualization of the } \\
\text { different types of } \\
\text { knowledge }\end{array}$ & P6, A4 \\
\hline $\begin{array}{l}\text { Bi- } \\
\text { directional } \\
\text { flows }\end{array}$ & $\begin{array}{l}\text { Visualize bi-directional } \\
\text { flows of data and } \\
\text { knowledge }\end{array}$ & $\begin{array}{l}\text { A2, A4, } \\
\text { A6, P1, P2 }\end{array}$ \\
\hline $\begin{array}{l}\text { Intensity of } \\
\text { flows }\end{array}$ & $\begin{array}{l}\text { Add intensity of flows } \\
\text { (quantification) to } \\
\text { balance acceptable risk } \\
\text { for expected return }\end{array}$ & P7, P8 \\
\hline $\begin{array}{l}\text { Visualization } \\
\text { of } \\
\text { Knowledge } \\
\text { Risks }\end{array}$ & $\begin{array}{l}\text { Potential knowledge } \\
\text { risks should be visually } \\
\text { marked for decision } \\
\text { makers when identified. }\end{array}$ & $\mathrm{A} 6, \mathrm{P} 7, \mathrm{P} 8$ \\
\hline $\begin{array}{l}\text { Knowledge } \\
\text { Boundary }\end{array}$ & $\begin{array}{l}\text { Misleading interpretation } \\
\text { of the visualization of the } \\
\text { knowledge boundary as a } \\
\text { security measure vs. } \\
\text { awareness measure. }\end{array}$ & $\begin{array}{l}\text { A2, P1, P7, } \\
\text { P9 }\end{array}$ \\
\hline
\end{tabular}

To identify and discuss potential knowledge risks, the different types of data-related value objects that are currently subsumed under data flows should be specified on a detailed level in the representation. A1 for instance pointed out that knowledge risks may arise from the transfer of data, or from the access to data (e.g. single queries), that are different kinds of data-related value objects. In this regard, a toolkit of sub-elements could be helpful. P5 underpins that as he mentioned that it is hard for people in practice to type elements in such network-based representations.

The type of knowledge should be also visualized in the representation. Involved knowledge could be expert knowledge from engineers, knowledge on the development of the algorithms or training of the model, or the knowledge on the application context. A representation should specify what knowledge is critical or confidential and what knowledge flow is uncritical or even necessary for the business model.

Our interviewees also mentioned that there are bidirectional flows of knowledge between actors that should be visualized, i.e. there are also knowledge flows from other actors (e.g., customers) to the business model owner. A6 for instance said:

"And what is missing here, you have one-sided flows of information and knowledge. [...] in a modern company, that learns from the customers, who also sends information to me. And knowledge as well. So, I would make bilateral flows". (A6*)

Thus, a DDBM could also create a knowledge risk for a customer or partner, when they transfer data to the business model owner. P1 for instance mentioned, if the business model owner wants to calculate a prediction for the customer, the customer has to transfer data to the business model owner that form the input for the prediction and thus could create a knowledge risk for the customer.

The exchanged value flows should be quantified, in order to conceive the trade-off between the potential risks and the estimated returns for management decisions or actions from the visualization. P8 for instance mentioned as a manager he needs more information, not only the titles but also the intensity of the flows. P7 further mentioned the approach to visualize this through the strength of the flow.

When identified, the potential knowledge risks should be visualized within the business model representation. As pointed out by $\mathrm{P} 7$ or P8, only the results of such an analysis are presented to executive management for decision. Thus, the visualization of the risks should be clear and easy to understand. P8 for instance suggested:

"I think it [the artifact] needs some more color. Risk is for me always associated with danger, which means I need something red somewhere." (P8*)

The visualization of the knowledge boundary was controversially discussed by the interviewees: P1 for instance mentioned that this approach is interesting to get this barrier into people's heads. On the contrary A2 for instance mentioned that such a barrier could assume that such a barrier could be technically possible. Interviewees P7 and P9 questioned the utility 
of the knowledge boundary and mentioned that the drain of knowledge could have been identified just by the flow elements.

\subsection{Expected benefit and fit of designed artifact to the problem}

The representation was found to be appropriate to discuss the different types of potential knowledge risks with the interviewed experts, to extend the model presented in section 3.1 and to think about other potential risks. The interviewees stated that they perceive the artifact in its current version as helpful to visualize and communicate knowledge risks and to create awareness for this problem. Table 3 provides exemplary statements as evidence for those expected benefits.

Further, our interviewees pointed out that in addition to the benefit of visualization, communication, and rising awareness; IS for managing knowledge risks in DDBMs also require the provision of actionable information to the management. Decision makers need clear and easy to understand conclusions and recommendations for decisions. P7 here for instance reported on his experience in a large organization:

"Often this practically fails because it is challenging to discuss very abstract relationships in practice. COMP works in such a way that decisions are made straight top down by senior management. [...] In the end, you should have a result that points to a very clear recommendation for action. That is the most important thing, also a learning that I had myself. [...] that you have a statement afterwards that you can write down in three sentences. Otherwise all the tools and methods are worthless. Because it does not influence the main decision, because the main decision makers cannot grasp it" (P7*).

As this interviewee stated, there is a demand for a low complexity of the visualization, but on the other hand interviewees request many details which should be included, such as weights or probabilities. Such details should include the assessment and quantification of the risk in terms of probability and impact, as for instance interviewee P8 noted:

"For me, risk always has something to do with probability. Thus, to add weighting somewhere, a risk weighting." (P8*)

In particular the estimation of the impact was desired as this is very important for balancing between potential risks and estimated return as one manager from industry mentioned:

"I think it's great if I can see at a glance, where are the risks, and how serious they are, because I want to be able to identify any management decisions at the end of the day." (P8*)

\section{Table 3. Statements to the expected benefit of the artifact.}

\begin{tabular}{|c|c|}
\hline & Exemplary Statements \\
\hline 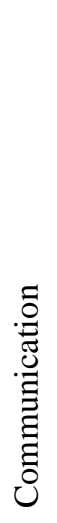 & $\begin{array}{l}\text { "What is the value of the tool? For me it is at this } \\
\text { point a pure communication of the service. Where } \\
\text { are the streams of data? If that is the purpose, then } \\
\text { it has value. Would I use it in practice? Yes, I could } \\
\text { imagine, if the network is complex enough. If I have } \\
\text { many data streams that I find difficult to } \\
\text { communicate. Then it can be a good } \\
\text { communication tool." (P9*) } \\
\text { "[...] if it's really about doing this as a core } \\
\text { business, then I should think about how I'm giving } \\
\text { the information to the outside world; and that the } \\
\text { different aspects you should think about, that } \\
\text { they'll come up for discussion, I think that's good." } \\
\text { (P2*) }\end{array}$ \\
\hline 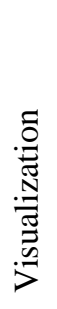 & $\begin{array}{l}\text { "Yeah, I think it is good. Because you can visualize } \\
\text { and see ok, this are the situations, I can exchange, } \\
\text { data and money and these are the dynamics, the } \\
\text { wall. I think that is more easily to see, visualize and } \\
\text { think about these relationships." (A3) } \\
\text { "This is some kind of flow modelling, of flows of } \\
\text { data, knowledge, money. I think it's pretty good for } \\
\text { visualization." (P6*) }\end{array}$ \\
\hline 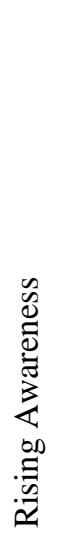 & $\begin{array}{l}\text { "Yes, it creates this awareness. [...] the warning } \\
\text { sign, to be aware of the fact of having the } \\
\text { distinction, to whom I offer the service and to } \\
\left.\text { whom not. I imagine that this can help." ( } \mathrm{P} 1{ }^{*}\right) \\
\text { "And it definitely makes sense to create awareness } \\
\text { that I need to think about it [the risks]." (P3*) } \\
\text { "If I just want it for awareness, a network thing } \\
\text { isn't bad." (P5*) } \\
\text { "I believe that this is already helpful for } \\
\text { companies, if they are aware of how knowledge } \\
\text { can leakfrom their own company borders, i.e. how } \\
\text { knowledge can leak and where the problem is } \\
\text { perhaps somewhat higher and where the problem } \\
\text { is perhaps not so high." (A4*) }\end{array}$ \\
\hline
\end{tabular}

In this regard, our interviewees request quantifications of all measures in regard to the risk:

"However, it [the tool] doesn't quantify the risk of data loss or the importance of the data in your company. Hence, the quantification is missing." (P1*)

Identifying and evaluating knowledge risk requires information on a more detailed level of granularity in addition to the abstract modelling of the flows and actors in the business model, in particular the detailed description of the flows of particular data and knowledge. Especially, the quantification of the exchanged value and the value of the knowledge is 
needed for balancing the risk is extremely challenging as one interviewee $\mathrm{P} 7$ resonates:

"And there you would need some understanding of how to measure money against data, how to measure the value of data, or the value of knowledge, or the value of predictions. This is, of course, very difficult." (P7*)

Our interviewees suggested questions to collect the required information. Table 4 presents such exemplary questions mentioned by our interviewees.

\section{Table 4. Exemplary assessment questions.}

\begin{tabular}{|l|l|}
\hline $\begin{array}{l}\text { Valuation } \\
\text { of data- } \\
\text { related } \\
\text { value } \\
\text { objects }\end{array}$ & $\begin{array}{l}\text { "Which data, which algorithms, which } \\
\text { actions are especially worth protecting, } \\
\text { company?" (P6*) } \\
\text { "Is the algorithm proprietary, so how } \\
\text { valuable is it? Can it be developed easy in } \\
\text { the beginning? Because he may or may not } \\
\text { have also the engineering skills." (P6*) }\end{array}$ \\
\hline $\begin{array}{l}\text { Data- } \\
\text { related } \\
\text { questions }\end{array}$ & $\begin{array}{l}\text { "Do I have any contractual obligations in } \\
\text { this data that I'm not allowed to give } \\
\text { away?" (P9*) } \\
\text { "Does the data give any inference to } \\
\text { something else of my company, like the } \\
\text { metadata, the meta-information of the } \\
\text { data? (P9*) } \\
\text { "Do only I have this data? Can the data } \\
\text { be generated or approximated by someone } \\
\text { else?" (P6*) }\end{array}$ \\
\hline $\begin{array}{l}\text { Model- } \\
\text { related } \\
\text { questions }\end{array}$ & $\begin{array}{l}\text { "At the model level I have to evaluate, is } \\
\text { such a model inversion possible, what } \\
\text { form does it reveal it?" (P9*) }\end{array}$ \\
\hline
\end{tabular}

\section{Discussion and Outlook}

Our interview study highlights that both practitioners and researchers in the fields of business models, data science and knowledge management are aware of knowledge risks arising from data-centric collaborations in DDBMs. Further, they agree on the potential usefulness of systematic support for assessing and monitoring such risks from the start of developing a DDBM. Such tool support doesn't exist so far. It was also mentioned that knowledge risks can be an important factor while taking the strategic decision on establishing or withholding a new DDBM. Thus, the present work contributes to the call for research on managing knowledge risks in strategic settings [31] and the call for risk management tools in business model innovation [44]. We contribute to the literature on business model innovation [2, 7, 8] by suggesting the consideration of knowledge risks already in the business model design supported by our artifact. Further it complements existing research on technical and organizational measures to manage knowledge risks in data-centric collaborations [27, 49] as well as methods for managing knowledge risks in general [24, 35].

Our study further showed that the network-based representation of business models was easy to understand, and was perceived as useful to discuss knowledge risks in a given DDBM. It was perceived as helpful as it visualizes the different flows of knowledge, money, and data between actors in the network and thus enable DDBM designers to identify unwanted outflows of knowledge and balance them with the exchanged benefits. Knowledge refers to an expert judgement what knowledge could be embedded in exchanged data. In terms of money, we focused only on business models with money-related flows in a B2B environment. We acknowledge that also nonmonetary returns exist in multi-sided revenue models of DDBMs (e.g., advertising or paying with data) [39]. Further research could adopt the artifact to such types of revenue models. Data refers to a type of exchange between actors in business models that needs to be describes as concretely as possible in the representation of each individual case.

Further, the discussions with our interviewees, and the derived design recommendations, highlight two elements of particular importance in the studied network-based representation, namely different types of value objects; and quantifications of risks. Both elements are a design recommendation for us for redesigning the artifact in further iterations. Specifically, these design recommendations call for clarification on what are key conceptual elements in considering risks in DDBM. We see both as valuable starting points for our future research.

Different types of value objects: Existing transaction-based representations of business models encompass flows of data [43] or flows of knowledge [40]. In DDBMs, different types of data-related value objects are exchanged, such as raw data streams, models or predictions. Thus, design recommendations from our interviews show that such nuanced differentiation of data-related value objects should be included as different types of exchanged entities in a network-based representation, as they have different characteristics in regard to knowledge risks.

Thus, further research could examine, how the types of exchanged value objects are associated with different types of, or different severity of, knowledge risks. Such nuanced distinction of exchanged values would need to discuss two fundamental questions of 
risk management: In what sense does this value object contain critical knowledge of an organization; and how easy it is to retrieve the knowledge from the shared value object. For instance, current research in computer science show, that and how machine learning models could be retrieved from sharing predictions via an API [47]. Such technical knowledge needs to be translated to risk assessment for DDBMs. Further, data value objects could of course also be classified concerning other characteristics, such as their licensing or publishing model.

Risk quantification: The evaluation interviews revealed that managing knowledge risks in DDBMs also requires an estimation of the probability (i.e., how easy is it to retrieve the knowledge) and the impact (i.e., what is the value of the leaked knowledge) of such risks as a decision input for the members of the DDBM design team. For such an estimation, collection of relevant data is needed. On the one hand our interviewees expressed their desire for comprehensive and quantifiably indicators, but on the other hand also see the practical challenges and efforts to collect the required data for such a decision support tool. Hence, a suitable balance needs to be found and tool support could help to lower the efforts of collecting the required data. Hence, research on how to collect the required data for our proposed networkbased representation best, seems an interesting research topic and a practical prerequisite for deployment in practice.

One avenue for supporting this data-collection could be the design of reflection prompts [14], attached to the elements of the representation as a qualitative support to increase the decision basis for the DDBM design team. Asking questions on business model design was researched as an evaluation approach for business models [17]. Such guiding questions could be automatically asked during the design process, when instantiating the artifact as a software implementation.

\section{Acknowledgements}

The research based on this paper has received funding from the Austrian COMET Program Competence Centers for Excellent Technologies under the auspices of the Austrian Federal Ministry of Transport, Innovation and Technology, the Austrian Federal Ministry for Digital and Economic Affairs and by the State of Styria. COMET is managed by the Austrian Research Promotion Agency (FFG).

\section{References}

[1] Allee, V., "Value network analysis and value conversion of tangible and intangible assets", Journal of Intellectual Capital, 9(1), 2008, pp. 5-24.

[2] Amit, R. and C. Zott, "Creating Value Through Business Model Innovation", MIT Sloan Management Review, 53(2), 2012, pp. 41-49.

[3] Bouwman, H., M. de Reuver, M. Heikkilä, and E. Fielt, "Business model tooling: where research and practice meet", Electronic Markets, 2020.

[4] Brillinger, A.-S., "Mapping Business Model Risk Factors", International Journal of Innovation Management, 22(05), 2018, 1840005.

[5] Brillinger, A.-S., C. Els, B. Schäfer, and B. Bender, "Business model risk and uncertainty factors: Toward building and maintaining profitable and sustainable business models", Business Horizons, 63(1), 2020, pp. 121-130.

[6] Casadesus-Masanell, R. and J.E. Ricart, Competing Through Business Models, Working Paper WP no 713, November, 2007.

[7] Chesbrough, H., "Business model innovation: It's not just about technology anymore", Strategy \& Leadership, 35(6), 2007, pp. 12-17.

[8] Chesbrough, H., "Business Model Innovation: Opportunities and Barriers", Long Range Planning, 43(2-3), 2010, pp. 354-363.

[9] https://bvdw.org/datadrivenbusinessmodels/.

[10] Dellermann, D., A. Fliaster, and M. Kolloch, "Innovation risk in digital business models: the German energy sector", Journal of Business Strategy, 38(5), 2017, pp. 35-43.

[11] Durst, S., "How far have we come with the study of knowledge risks?", VINE Journal of Information and Knowledge Management Systems, 49(1), 2019, pp. 21-34.

[12] Durst, S. and M. Zieba, "Mapping knowledge risks: towards a better understanding of knowledge management", Knowledge Management Research \& Practice, 17(1), 2018, pp. 1-13.

[13] Engelbrecht, A., J. Gerlach, and T. Widjaja, "Understanding the anatomy of data driven business models - towards an empirical taxonomy", in ECIS 2016 Proceedings, 2016.

[14] Fessl, A., G. Wesiak, V. Rivera-Pelayo, S. Feyertag, and V. Pammer, "In-app Reflection Guidance: Lessons Learned across Four Field Trials at the Workplace.", EEE Transactions on Learning Technologies, 10(4), 2017, pp. 488-501.

[15] Fruhwirth, M., V. Pammer-Schindler, and S. Thalmann, "To Sell or Not to Sell: Knowledge Risks in DataDriven Business Models", 2019 Pre-ICIS SIGDSA Symposium, Munich, 2019.

[16] Fruhwirth, M., C. Ropposch, and V. Pammer-Schindler, "Supporting Data-Driven Business Model Innovations: A structured literature review on tools and methods", Journal of Business Models, 8(1), 2020, 7-25.

[17] Gilsing, R., O. Turetken, Ozkan, Baris, Adali, Onat Ege, and P. Grefen, "A method for qualitative evaluation of service-dominant business models", In ECIS 2020 Proceedings, 2020.

[18] Gordijn, J. and H. Akkermans, "Designing and evaluating e-business models", IEEE Intelligent 
Systems, 16(4), 2001, pp. 11-17.

[19] Guggenberger, M.T., F. Möller, K. Boualouch, and B. Otto, "Towards a Unifying Understanding of Digital Business Models", In PACIS 2020 Proceedings, 2020.

[20] Hartmann, P.M., M. Zaki, N. Feldmann, and A. Neely, "Capturing value from big data - a taxonomy of datadriven business models used by start-up firms", International Journal of Operations \& Production Management, 36(10), 2016, pp. 1382-1406.

[21] Hevner, A., S. March, J. Park, and S. Ram, "Design Science in Information Systems Research", Management Information Systems Quarterly, 28(1), 2004, pp. 75-105.

[22] Hirt, R. and N. Kühl, "Cognition in the Era of Smart Service Systems: Inter-organizational Analytics through Meta and Transfer Learning", in ICIS 2018 Proceedings, 2018.

[23] Hunke, F., C. Engel, R. Schüritz, and P. Ebel, "Understanding the Anatomy of Analytics-Based Services: A Taxonomy to Conceptualize the Use of Data and Analytics in Service", in ECIS 2019 Proceedings, 2019.

[24] Ilvonen, I., J. Jussila, H. Karkkainen, and T. Paivarinta, "Knowledge Security Risk Management in Contemporary Companies -- Toward a Proactive Approach", 48th Hawaii International Conference on System Sciences, 2015, pp. 3941-3950.

[25] Ilvonen, I., S. Thalmann, M. Manhart, and C. Sillaber, "Reconciling digital transformation and knowledge protection: a research agenda", Knowledge Management Research \& Practice, 16(2), 2018, pp. 235-244.

[26] Jennex, M.E. and S. Zyngier, "Security as a contributor to knowledge management success", Information Systems Frontiers, 9(5), 2007, pp. 493-504.

[27] Kaiser, R., S. Thalmann, and V. Pammer-Schindler, "An Investigation of Knowledge Protection Practices in Inter-organisational Collaboration: Protecting Specialised Engineering Knowledge with a Practice Based on Grey-box Modelling", VINE Journal of Information and Knowledge Management Systems, 2020.

[28] Kronsbein, T. and R.M. Mueller, "Data Thinking: A Canvas for Data-Driven Ideation Workshops", in Proceedings of the 52nd Hawaii International Conference on System Sciences, 2019.

[29] Kühne, B. and T. Böhmann, "Data-Driven Business Models: Building the Bridge Between Data and Value", in ECIS 2019Proceedings, 2019.

[30] Lee, J., J. Min, and H. Lee, "Setting a Knowledge Boundary for Enhancing Work Coordination and Team Performance: Knowledge Protection Regulation across Teams", in ICIS 2015 Proceedings, 2015.

[31] Loebbecke, C., P.C. van Fenema, and P. Powell, "Managing inter-organizational knowledge sharing", The Journal of Strategic Information Systems, 25(1), 2016, pp. 4-14.

[32] Manhart, M. and S. Thalmann, "Protecting organizational knowledge: a structured literature review", Journal of Knowledge Management, 19(2), 2015, pp. 190-211.
[33] Massingham, P., "Knowledge risk management: a framework", Journal of Knowledge Management, 14(3), 2010, pp. 464-485.

[34] Mayring, P., Qualitative Inhaltsanalyse: Grundlagen und Techniken, 12th edn., Beltz, Weinheim, 2015.

[35] Padyab, A.M., T. Paivarinta, and D. Harnesk, "GenreBased Assessment of Information and Knowledge Security Risks", pp. 3442-3451.

[36] Peffers, K., T. Tuunanen, M.A. Rothenberger, and S. Chatterjee, "A Design Science Research Methodology for Information Systems Research", Journal of Management Information Systems, 24(3), 2007, pp. 45-77.

[37] Schneider, S. and P. Spieth, "Business Model Innovation: Towards an integrated future research agenda", International Journal of Innovation Management, 17(01), 2013, p. 1340001.

[38] Schüritz, R., K. Farrell, B.H. Wixom, and G. Satzger, "Value Co-Creation in Data-Driven Services: Towards a Deeper Understanding of the Joint Sphere", In ICIS 2019 Proceedings, 2019.

[39] Schüritz, R., S. Seebacher, and R. Dorner, "Capturing Value from Data: Revenue Models for Data-Driven Services", in Proceedings of the 50th Hawaii International Conference on System Sciences, 2017.

[40] Solaimani, S., H. Bouwman, and T. Itälä, "Networked enterprise business model alignment: A case study on smart living", Information Systems Frontiers, 17(4), 2015, pp. 871-887.

[41] Sonnenberg, C. and J. Vom Brocke, "Evaluation in the Science of the Artificial: Reconsidering the BuildEvaluate Pattern in Design Science Research", in DESRIST 2012 Proceedings, 2012.

[42] Täuscher, K. and N. Abdelkafi, "Visual tools for business model innovation: Recommendations from a cognitive perspective", Creativity and Innovation Management, 26(2), 2017, pp. 160-174.

[43] Terrenghi, N., J. Schwarz, and C. Legner, "Towards Design Elements to Represent Business Models for Cyber Physical Systems", in ECIS 2018 Proceedings.

[44] Tesch, J. and A.-S. Brillinger, "The Evaluation Aspect of Digital Business Model Innovation: A Literature Review on Tools and Methodologies", in ECIS 2017 Proceedings, 2017.

[45] Thalmann, S. and I. Ilvonen, "Why Should We Investigate Knowledge Risks Incidents? - Lessons from Four Cases", in Proceedings of the 53rd Annual Hawaii International Conference on System Sciences 2020.

[46] Timmers, P., "Business Models for Electronic Markets", Electronic Markets, 8(2), 1998, pp. 3-8.

[47] Tramèr, F., F. Zhang, A. Juels, M.K. Reiter, and T. Ristenpart, "Stealing Machine Learning Models via Prediction APIs", Proceedings of the 25th USENIX Security Symposium, 2016, pp. 601-618.

[48] Venable, J., J. Pries-Heje, and R. Baskerville, "FEDS: a Framework for Evaluation in Design Science Research", European Journal of Information Systems, 25(1), 2016, pp. 77-89.

[49] Zeiringer, J.P. and S. Thalmann, "Knowledge Risks in Digital Supply Chains: A Literature Review", 15. Internationale Tagung Wirtschaftsinformatik, 2020. 